\title{
Construcción de la cultura de apreciación de la fruta aporte de Las mil y una noches*
}

\section{Building the culture of appreciation of the fruit contribution of Arabian Nights*}

PABLO LACOSTE Profesor titular del Instituto de Estudios Avanzados de la USACH Román Díaz 89, Providencia, Santiago de Chile pablo.lacoste@usach.cl

AMALIA CASTRO Profesora de la Universidad Católica Silva Henríquez General Jofré 462 - Santiago - Chile castrosancarlos@yahoo.com.mx

JOSÉ ANTONIO YURI Ingeniero agrónomo, director del Centro de Pomáceas de la Universidad de Talca 2 Norte 685 - Talca - Chile ayuri@utalca.cl

RESUMEN Este artículo examina al aporte de los árabes al proceso de construcción de la cultura de apreciación de la fruta y los frutales. Se avanzó en esa dirección no sólo mediante la incorporación y propagación de las plantas, particularmente desde Al Andalus, sino también con su puesta en valor en la cultura universal, a través de Las mil y una noches. Si los botánicos y agrónomos andalusíes aportaron avances científicos sobre las plan-

* Artigo recebido em: 04/10/2011. Aprovado em: 04/02/2012.

** Este trabajo es resultado del proyecto Fondecyt 1080210. Los autores desean agradecer los aportes de Expiración García Sánches (España) y Viviana Bosio (Argentina). 
tas frutales y la forma de cultivarlas y aprovecharlas, los relatos literarios de la cultura islámica complementaron la acción de aquellos, al situar las frutas y los frutales en el centro del imaginario social, en los lugares de mayor prestigio (jardines, palacios, salones) y asociarlos a la sensualidad, la belleza y el placer.

Palabras clave intermediadores bioculturales, historia de la fruticultura, apreciación de la fruta, Las mil y una noches

ABSTRACT: This article examines what the Muslim world contributed to the materialization of a cultural appraisal of fruits and the trees that bear them. This contribution was not only carried out through the propagation and incorporation of these plants, particularly from Al Andalus, but also by providing them with considerable cultural significance with their inclusion in Arabian Nights. While Andalusian botanists and agronomists achieved significant scientific breakthroughs in the methods involved in the cultivation and proper utilization of fruit trees, Muslim literary tales complimented these developments by placing both fruits and fruit trees in the cultural spotlight, in highly prominent locations (gardens, palaces, halls) and by bonding them with sensuality, beauty and pleasure. Muslims acted as biocultural intermediaries.

Keywords biocultural intermediaries, fruit culture history, fruit appreciation, Arabian Nights

Doña Agustina Echegaray enviudó cuando tenía escasos bienes y una hija recién nacida. A partir de entonces, y durante veinte años, se dedicó a cultivar sus plantas frutales: manzanos, granados, olivos y almendros, entre otros. El parral de moscatel y los naranjos eran su orgullo, pues junto a ellos compartía momentos entrañables con sus seres queridos. Esos frutales eran su tesoro y el legado para su hija. Así lo indicó en su testamento, dado en San Juan, Reino de Chile, en la frontera austral del Imperio español. ${ }^{1}$ Como ella vivieron muchos otros vecinos - casi la mayoría - de ese rincón del mundo. Algo movía interiormente a los vecinos del cono sur de América a dedicar tiempo y esfuerzo para cultivar esas plantas. No podían, seguramente, predecir que siglos más tarde, Chile y Argentina,

El huerto tenía seis manzanos, dos naranjos, cinco albaricoques, dos almendros, dos olivos, seis perales, seis granados, veinte durazneros y un parral de uva moscatel. Inventario de los bienes de Doña Agustina Echegaray. San Juan. Archivo del Poder Judicial de San Juan. Libro Joseph Sebastián de Castro, Protocolo 1770, Folio 108, 10 de noviembre de 1770 . 
junto a Brasil, emergerían como potencias mundiales de fruticultura. ${ }^{2}$ Tampoco sabían de las cualidades de las frutas para la salud. ${ }^{3}$ Pero se mantuvieron fieles a un proyecto debido al valor simbólico y cultural que atribuían a esas plantas.

Estudiar el proceso de apreciación de determinados elementos es un tema de creciente interés. Los estudios de Alan Corbin sobre el proceso de construcción de la playa como espacio social son un clásico. ${ }^{4}$ En una dirección equivalente pueden situarse los trabajos sobre construcción de la cultura de apreciación del vino. ${ }^{5}$ Las investigaciones realizadas en este nuevo campo del conocimiento han demostrado una fecundidad notable, pues permite explicar procesos complejos que hasta hace poco tiempo, permanecían invisibles. Siguiendo esta línea, el presente artículo se interesa en los frutales y la fruta.

La cultura de la apreciación de la fruta y los frutales se construyó a través de un largo proceso, en el cual los musulmanes hicieron un aporte sensible, tanto desde el punto de vista botánico y agronómico como en el plano cultural. Conocido es el papel que cupo a los árabes en el cultivo y estudio de las plantas frutales, reflejado en los manuales de los agrónomos andalusíes. ${ }^{6}$ Esa labor con las plantas reales se complementó con otra, no menos importante: poner las frutas y los frutales en valor en el imaginario social. Así se reflejó en la máxima obra de la literatura árabe: Las mil y una noches.

En la Edad Media, la fruta ocupaba un papel muy secundario en las prácticas alimentarias de Europa. Las élites consumían carnes y pescados, mientras que el pueblo se alimentaba principalmente con cereales y legumbres. La presencia de las frutas quedaba reducida a algunas manzanas y peras, ocasionalmente. ${ }^{7}$ Los huertos de castillos y monasterios cultivaban algunas plantas frutales, pero preferentemente orientadas a productos de valor simbólico como licores

2 Chile cultiva 324.000 hectáreas de plantas frutales y Argentina casi el doble. Como productores mundiales, se destacan en ciruelas (Chile $5^{\circ}$, Argentina $\left.14^{\circ}\right)$, duraznos $\left(11^{\circ}\right.$ y $\left.10^{\circ}\right)$, peras $\left(15^{\circ}\right.$ y $\left.5^{\circ}\right)$, limones y $\operatorname{limas}\left(14^{\circ}\right.$ y $\left.3^{\circ}\right)$, uva $\left(8^{\circ}\right.$ y $\left.7^{\circ}\right)$ y manzanas $\left(10^{\circ}\right.$ y $\left.11^{\circ}\right)$; FAO. Food and Agriculture Organization of the United Nations. Statistics 2010 Data Now Available. http://faostat.fao.org/site/339/default.aspx. Fecha consulta: 28 jun. 2012.

3 SCARBOROUGH, Peter; NNOAHAM, Kelechi; CLARKE, Dushy; CAPEWELL, Simon e RAYNER, Mike. Modelling the impact of a healthy diet on cardiovascular disease and cancer mortality. Journal of Epidemiology Community Health, London, n.114520, 2010.

4 CORBIN, Alain. Le territoire du vide: l'Occident et le désir du rivage, 1750-1840. Paris: Aubier, 1988.

5 DUHART, Frédéric. La moral y el gusto: el vino en Le Mesnagier de Paris (siglo XIV). Universum, Talca, Talca, n.22, p.95-101, 2007. LACOSTE, Pablo y DUHART, Frédéric. Los vinos de D'Artagnan: evocaciones y funciones del vino en el ciclo de los mosqueteros de Alejandro Dumas. En: DUHART, Frédéric y PÁEZ, Sergio Corona. (eds.). Los vinos de Europa y América: catorce miradas desde las ciencias del hombre. París: Le Manuscrit, Colección IBERVITIS Viticultura y Ciencias Sociales, 2010, p.313-339.

6 BRAVO, Julia María Carabaza; SÁNCHEZ, Expiración García; BERMEJO, Esteban Hernández y RAMÍREZ, Alfonso Jiménez. Árboles y arbustos en Al-Andaluz. Madrid: CSIC, 2004.

7 MENNELL, Stephen. Francais et Anglais a table du moyen age a nos jours. Paris: Flammarion, 1987, p.73-74. 
y tinturas. $^{8}$ Las aceitunas y el aceite de oliva, relativamente extendidos en la antigüedad debido a la Pax Romana, decayeron en el Medioevo por la crisis institucional y comercial. En este contexto se produjo la expansión musulmana a Europa a través de al-Andalus, con la cual ingresó la cultura de la apreciación de la fruta.

Los pueblos árabes y la cultura musulmana en general, tuvieron un papel protagónico en un proceso mayor, a través del cual se produjo la introducción y propagación de las plantas frutales en Europa. Manzanos, perales, membrilleros, durazneros y damasqueros fueron domesticados en Asia Central y desde allí se trasladaron a medio oriente medio primero y a Europa después. 9 "Alejandro Magno trajo el peral de Persia; los romanos trajeron el duraznero en el siglo I; los árabes encontraron el albaricoque en Armenia en el siglo VIII". ${ }^{10}$ Más tardíos son los cítricos, originarios del sudeste asiático. Los árabes los trasladaron desde la India en el siglo X, particularmente el naranjo amargo, el limonero y el limo. ${ }^{11}$

Los pueblos de medio oriente en general y los árabes en particular, tuvieron un liderazgo notable en la historia de la fruticultura, tal como se refleja en los nombres científicos y vulgares de estas plantas. ${ }^{12} \mathrm{El}$ imperio romano significó un fuerte avance en el proceso de propagación y difusión de los frutales. Pero después de su caída se produjo un retroceso importante. El consumo de frutas en Europa quedó restringido a grupos privilegiados en castillos y monasterios. Sin embargo, mientras la Europa medieval perdía la cultura de la fruta, ésta se fortalecía en el mundo árabe, particularmente en los jardines y huertos de Bagdad y Basora, de Damasco y El Cairo. En medio oriente y el norte de África, los árabes mantuvieron intacta la tradición de cultivar, valorar y compartir las plantas frutales. A diferencia de sus vecinos europeos, los árabes mantuvieron y enriquecieron el patrimonio cultural frutícola heredado de la antigüedad, patrimonio que extendieron con sus conquistas. Ello se hizo evidente, por ejemplo, en los tratados de botánicos y agrónomos andalusíes. Los musulmanes impulsaron el cultivo

8 CADENA, Francisco Páes de la. Historia de los estilos en jardinería. Madrid: Akarl, 1982, p.113.

9 MONTERO, Raúl. El damasco. Buenos Aires: Atlántida, 1946, p.6. PELT, Jean-Marie; MAYOYER, Marcel; MONOD, Théodore y GIRARDON, Jacques. La historia más bella de las plantas: las raíces de nuestra vida. Barcelona: Anagrama, 2001, p.139.

10 PELT, Jean-Marie; MAYOYER, Marcel; MONOD, Théodore y GIRARDON, Jacques. La historia más bella de las plantas, p.139.

11 CASTAÑER, Manuel Amorós. Producción de agrios. Madrid: Mundi-Prensa, 2003, p.21-23.

12 El albaricoque, Prunus armeniaca, se llama también damasco por su presencia en la ciudad homónima de Siria. El cidro, llamado también "limón turco", es Citrus medica; el duraznero es Prunus persica. Otras frutas tienen nombres en español derivados del árabe: naranjo (narany), lima y limón (laymun, lim), aceituna (zaytun), sandía (sindiyyah) y avellano (yillawz); BRAVO, Julia María Carabaza; SÁNCHEZ, Expiración García; BERMEJO, Esteban Hernández y RAMÍREZ, Alfonso Jiménez. Árboles y arbustos en Al-Andaluz. 
de diversas plantas frutales tanto en Sicilia como en la península ibérica. Ellos reintrodujeron frutales que se habían cultivado allí durante el imperio romano y, además, aportaron plantas nuevas, principalmente los cítricos (naranjo amargo, limonero, limo, cidro) presentes en el espacio hispanoárabe desde los siglos XII y XIII. ${ }^{13}$ Los musulmanes incorporaron la fruta no sólo a la mesa de las elites, sino también a las capas populares. Sus avanzados conocimientos sobre fruticultura permitieron el incremento de producción y el abastecimiento de los zocos, donde el pueblo acudía a comprar sus frutas en cantidades que hubieran asombrado a cualquier europeo del medioevo. ${ }^{14}$

Los nuevos reinos cristianos, emergidos de la reconquista, se apropiaron del empuje de los árabes en favor de las frutas. ${ }^{15}$ En el siglo XVII se destacaban las plantaciones de naranjos, limoneros y olivos en Portugal y España. ${ }^{16}$ Cuando estos reinos iniciaron su expansión por el mundo, llevaron consigo este patrimonio biocultural. La fruticultura se proyectó hacia las Indias, donde portugueses y españoles trasladaron sus hábitos de producción y consumo. Algunas regiones donde los nichos ecológicos eran adecuados, lograron importantes avances en el campo de la fruticultura.

La irradiación cultural de los árabes se produjo no sólo con sus prácticas cotidianas, sus usos y costumbres, sino también con sus expresiones culturales y artísticas, entre las cuales la literatura fue un vehículo significativo. En este lugar ubicamos a Las mil y una noches que, junto con el Corán, "componen la literatura más popular de Oriente". ${ }^{17}$ Estos cuentos han fascinado a generaciones de lectores y auditores, hasta constituirse en el principal aporte de la cultura árabe a la literatura universal. ${ }^{18}$

¿Qué decían los cuentos de Las mil y una noches sobre los frutales y la fruta? ¿En qué medida estaban presentes estos alimentos en la vida cotidiana de los árabes? ¿Qué se valoraba de ellos? ¿Con qué otros aspectos se vinculaban? Despejar estas incógnitas puede servir para comprender mejor la importancia que el tema de la fruta tenía para la cultura árabe, y sus proyecciones hacia Europa. La literatura especializada coincide en destacar la profundidad de la influencia de Las mil y una noches en buena parte de la

13 CASTAÑER, Manuel Amorós. Producción de agrios, p.23.

14 SÁNCHEZ, Expiración García. La gastronomía andalusí. En: VVAA. El zoco: vida económica y artes tradicionales en Al Andaluz y Marruecos. Barcelona: Lunwerg Editores, 1995, p.49-57.

15 COSTA, Adelaide Pereira Millán da e GONCALVES, Iria. O espaço urbano e o espaço rural. In: MATOSO, José. (dir.) História da vida privada em Portugal: a Idade Média. Coímbra: Círculo de Leitores/Temas e Debates, 2010, p.46.

16 DELFOURNEAUX, Marcelin. La vie quotidienne en Espagne au siecle d'or. Paris: Hachette, 1964, p.14-15.

17 ACKERLEY, María Isabel. Borges, el islam y la búsqueda del otro. Eikasia Revista de Filosofía, Oviedo, v.II, n.7, p.69, noviembre 2006.

18 MARZOLPH, Ulrich and LEEUWEN, Richard van. The Arabian nights encyclopedia. California: ABC-Clio, 2004. 
literatura de Occidente, desde la Edad Media hasta la actualidad, tanto en Europa como en América. ${ }^{19}$

La obra ha fascinado a la cultura universal, generando numerosos estudios sobre temas específicos, tanto desde el punto de vista literario como de las costumbres que allí se reflejan. En algunos casos, la crítica se ha focalizado en temas alimentarios, como descubrimiento fortuito de nuevas formas de elaboración, que luego inspiraron otras obras literarias.

Antes de examinar cualitativamente las representaciones de la fruta en Las mil y una noches, conviene considerar la mirada cuantitativa. Es importante comenzar por identificar la magnitud de la presencia del tema, identificar las especies más mencionadas y las cifras más generales. Las referencias corresponden a la edición de Megalibros aunque en forma complementaria hemos usado también la edición de Anaconda. ${ }^{20}$

\section{Frutas y frutales en la obra: aspectos cuantitativos}

La presencia de la fruta y los frutales en Las mil y una noches es un fenómeno muy notable, pues comprende 868 referencias directas. ${ }^{21}$ Ello representa una densidad importante, compartida en buena medida por una obra de la antigüedad, y de una dimension equivalente, como el caso de la Biblia (695 menciones a frutas y frutales), y muy superior a la literatura medieval europea, donde la fruta aparece en forma muy esporádica: en el Canto de los Nibelungos hay una mención de fruta, lo mismo que en el poema del Mío Cid; en Beowulf ninguna; en Chanson de Roland 6; Divina Comedia 6; Decamerón 34, y 52 en los Cuentos de los Hermanos Grimm, obra compilada tardíamente pero basada en relatos medievales. ${ }^{22}$ La superioridad de la valoración de la

19 URBINA, Nicasio. Las mil y una noches y Cien años de soledad: falsas presencias e influencias definitivas. $M N L$, Maryland, n.107, v. 2, p. 321-341, mar 1992. VERNET, Juan. Las mil y una noches y su influencia de la novelística medieval española. Boletín de la Real Academia de Buenas Letras de Barcelona, Barcelona, p.5-25, 1959. WAISMAN, Sergio. The legacy of the thousand and one nights in Argentina: translation, narrative and politics in Borges, Puig and Piglia. In: HAMILTON, Michelle; PORTNOY, Sarah, and WACKS, David. (eds.) Wine, women and song: Hebrew and Arabic literature of medieval iberia. Newark, DE: Juan de la Cuesta, 2004. PEDROSA, José Manuel. Pan de adárgama y vino de sorgo: las mil y una noches (noche 580), el Sendebar (cuento 4) y el Sorgo Rojo de Ma yan y una vieja historia de Miguel Delibes. Revista de poética medieval, Alcalá de Henares, n.10, p.101-108, 2003. MACGRADY, Donald. Un cuento de las mil y una noches en Boccaccio, Lope de Vega, Calderón, Corneille, Lesage y otros. Bulletin hispanique, Bordeaux, n.1, p.465-481, 2003.

20 ANÓNIMO. Las mil y una noches. Traducción española basada en la versión francesa de Mardus. Buenos Aires: Megalibro, 2009, 2t, 1428 páginas. ANÓNIMO. Las mil y una noches. Traducción directa y literal del árabe por el doctor J.C.Mardrus. Versión española de Vicente Blasco Ibáñez. Prólogo de E. Gómez Carrillo. Basada en la versión francesa de Mardus. Buenos Aires: Anaconda, 2002, 6t, 1822 páginas.

21 Se incluyen 222 referencias genéricas (frutas y árboles frutales en general) y 646 especies definidas.

22 ROJAS, Matías. La fruta en la literatura medieval. En: V Workshop Frutales y sociedad en Chile. Santiago, Universidad de Santiago, 7 de enero 2011. Sagrada Biblia. Barcelona: Editors SA, 1984. 
fruta en Las mil y una noches es incontrastable. Las menciones comprenden frutas como objetos o bien como referencia para explicar las cualidades de una persona o cosa (color, tamaño, textura, turgencia). La fruta como objeto se divide en tres grupos: la planta frutal (54 casos), la fruta natural (382) y la fruta elaborada (86). También encontramos la utilización de la fruta en sentido metafórico, en 34 menciones que aluden a color o tamaño y en 90 donde toman el lugar de alguna parte del cuerpo o nombre de persona.

Después de constatar la presencia de las frutas en Las mil y una noches, conviene distinguir las distintas funciones que ocupan dentro de ese universo literario. Para avanzar en esta dirección, ha sido preciso agrupar las referencias a las frutas de acuerdo con elementos comunes, y descubrir así el criterio que han tenido los autores del texto para incluir a las frutas en su elaboración. En este sentido, se distinguen cinco funciones principales: erótica, sanitaria, gastronómica, bioespacial e identitaria. De todos modos, cada una de estas categorías tiene suficiente entidad para sostenerse, pues incluye casos representativos por su relevancia cuantitativa o cualitativa, lo cual permite comprender mejor los principales sentidos que los autores de esta obra le brindaron a la fruta.

\section{La fruta como metáfora de la sensualidad femenina}

El erotismo es uno de los temas más importantes de Las mil y una noches. La fuerza del erotismo en la obra es tan notable, que ha generado ediciones específicas con dicha perspectiva. Uno de los primeros antecedentes fue el libro de Dehoi, al cual siguieron muchos más, entre ellos, la edición (y reedición) del libro Cuentos eróticos de las mil y una noches (1986). La problemática del erotismo en estos escritos ha despertado un amplio interés en el mundo académico. ${ }^{23}$ Esas obras han permitido avanzar en aspectos

23 DEHOï, Enver F. L'érotisme des mille et une nuits. Paris: Jean-Jacques Pauvert, 1961; SOBH, Mahmud. Islas afortunadas en las mil y una noches. Anaquel de Estudios Arabes, Madrid, n.12, p.715-718, 2001. SOBH, Mahmud y GIRELA, Francisco Ruiz. (trad. y sel.) Cuentos eróticos de las mil y una noches. Madrid: Silex, 1986. FERRER, J.M. Continente. Aproximación al estudio del amor en la poesía hispano-árabe de los siglos XII y XII. Awraq, Madrid, n.1, p.12-28, 1978. GUERRERO, Rafael Ramón. Erótica y saber: a propósito de un cuento de las mil y una noches. Anales del Seminario de Historia de la Filosofía, Madrid, n.16, p.15-34, 1999. MOSHABI, Hassouna y HELLER, Erdmute. Tras los velos del Islam: erotismo y sexualidad en la cultura árabe. Barcelona: Herder, 1995. COLLIGAN, Colette. Esoteric pornography: Sir Richard Burton's Arabian nights and the origins of pornography. Victorian Review, Victoria, n.28, v.2, p.31-64, 2002. MALTI-DOUGALAS, Fedwa. Homosociability, heteroxexuality and Shahrazad. In: MARZOLPH, Ulrich and LEEUWEN, Richard van. The Arabian nights encyclopedia, p.38-41; LYNN, Ramey. Crossing borders: love between women in medieval French and Arabic literatures (review). Arthuriana, Dallas, Texas, n.20, v.2, p.127-130, summer 2010. CHEBEL, Malek. Encyclopédie de l'amour en Islam, érotisme, beauté et sexualité dans le monde arabe, en Perse et en Turquie. Paris: Payot, 1995. 
específicos del erotismo: desde la censura hasta la homosexualidad, pasando por exhibicionismo y fetichismo, lo cual ha permitido comprender mejor su sentido dentro de las culturas árabes en general y de Las mil y una noches en particular.

Dada la perspectiva del presente trabajo, centrada en los frutales y la fruta, el foco no se ubica en el erotismo en sí mismo, sino en el papel que cupo a las frutas en el despliegue de la dimensión erótica de la obra. Erótico es algo "perteneciente o relativo al amor sensual, que excita el apetito sexual". ${ }^{24}$ Desde esta perspectiva, el objetivo es identificar la función de la fruta como recurso del autor para destacar la belleza y estimular el deseo.

En el marco de un entorno cultural, signado por la costumbre de cubrir el cuerpo con velos y burkas, la mujer era relativamente invisible para el hombre. Esto generaba un interés especial por las imágenes de la mujer, lo cual fue muy bien explotado en Las mil y una noches: al destacar la sensualidad de la mujer, se incrementaba el interés y la tensión dramática del relato en su conjunto. Por lo tanto, los relatos ponían mucha energía en destacar la belleza y sensualidad de las mujeres. Y precisamente en esta tarea, las frutas prestaban una ayuda notable, pues permitían elaborar descripciones cargadas de voluptuosidad y erotismo. Las frutas, al usarse en forma comparada con el cuerpo de la mujer, contribuían a excitar el apetito sexual de los hombres a los cuales estaba dirigido el relato.

La apelación a la fruta para compararla con la mujer y resaltar sus características, fue un recurso literario empleado en los textos antiguos y medievales. Así, por ejemplo, en la Biblia se hace referencias a uvas y manzanas con este objetivo (Cant 6:9; 6:7). ${ }^{25}$ Por su parte, Boccaccio también empleó este recurso para realzar la belleza de una mujer. ${ }^{26}$ Estos ejemplos ilustran la tradición literaria de comparar la mujer con las frutas; hubo intentos de apelar a la turgencia de la fruta para lograr una descripción más atractiva de la mujer, pero sin llegar al nivel de sensualidad alcanzado por Las mil y una noches.

La comparación de la fruta con personas se orientaba casi siempre a destacar la belleza y sensualidad de una mujer. Sobre un total de 90 casos, 88 corresponden a mujeres y sólo dos a un varón adolescente, cuyo rostro se compara con los dátiles. En todos los demás ejemplos, la atención está vertida hacia la mujer, objeto del deseo de los varones.

24 RAE. Diccionario de la lengua española. Madrid: Espasa Calpe, 1992, 19 ed. I, p.865.

25 El texto usa las siguientes abreviaturas de textos bíblicos: Gén: Genesis; Éx: Éxodo; Núm: Números Dt: Deuteronomio; I Sam: I Samuel; I Re: I Reyes; I Crón: I Crónicas; Cant: Cantar de los Cantares; Is: Isaías; Neh: Nehemías; Ecco: Eclasiástico.

26 BOCCACCIO, Giovanni. Decamerón. Introducción de Francisco José Alcántara. Versión castellana de 1496 actualizada por OLIVAR, Marcial. Barcelona: Planeta, 1999 [1351], III/4, p.161. 
Para enfatizar el carácter sensual y atractivo del cuerpo de la mujer, la fruta servía como un recurso práctico y eficaz, con múltiples variables. El mecanismo más habitual era destacar las cualidades compartidas por las frutas y el cuerpo de la mujer: formas, sabores, olores y texturas (872:483; 336:533).

Con frecuencia, la descripción se focaliza en las partes más eróticas de la mujer: senos, nalgas y vulva. Los senos se comparan con peras o granadas (75:239; 9:36; 270:457; 379:588). En realidad, los casos más recurrentes de comparación de los pechos eran con las granadas. Por su parte, los pezones se asocian a las uvas (206:394). La asociación de cada parte del cuerpo con una fruta, abría la posibilidad de un juego sensual muy dinámico: "Mi cuerpo es un vergel, cuyos frutos son: las granadas, mis senos; los melocotones, mis mejillas; las sandías, mis nalgas" (336: 532).

Para reconocer la virginidad de una mujer, se comparaban sus órganos con una almendra $(689: 242 ; 690: 242 ; 690: 244)$. Por otra parte, las nalgas de una mujer corpulenta se comparaban con una sandía. El cabello y el rostro de la mujer también se comparaban con fruta para resaltar su sensualidad. A través de imágenes intensas, se establece un paralelismo lúdico e insinuante. El empleo de la pareja conceptual cabello-racimo de uva, resulta un buen ejemplo: "suelto el cabello, que cae en cascada sobre sus hombros, recuerda los racimos de la cepa, rubios o morenos" (46:201).

Los ojos de una mujer fina y elegante se asociaban con las almendras. La barbilla se comparaba con la manzana. (898:557). La tersura de las mejillas se comparaba con el durazno y la piel sedosa con el damasco. La boca de la mujer es destacada con interés; por un lado, se destacaba la saliva, elixir sensual que excita los sentidos "más dulce que el jugo valioso de las uvas" (649:195). Por otro, los labios se comparan con granadas y pistachos. La referencia a la granada apunta a resaltar tanto su color como su dimensión sensitiva (157:358). La intensidad del color rojo de la granada permite resaltar de una manera casi hiperbólica, la tonalidad de los labios de la mujer, para alcanzar una imagen más atrayente e idealizada. Cuando los labios se comparan con el pistacho, se procura destacar su encanto y sabor, combinados a veces, con otras frutas (922:592). Incluso, las extremidades de la mujer eran objeto de descripción sensual mediante comparaciones con frutas (748:315).

\section{La fruta como fuente de salud}

La función sanitaria es otra característica importante de las frutas. Sanitario es lo "perteneciente o relativo a la sanidad", entendiendo por este último concepto la "cualidad de sano", o bien "el conjunto de servicios 
para preservar la salud de los habitantes de una nación, provincia, etc". ${ }^{27}$. En este terreno, las frutas, en cuanto alimento rico en vitaminas y otros nutrientes, representan un aporte significativo. De todos modos, el proceso por el cual se detectaron y valoraron estas cualidades fue muy lento. Algunos médicos importantes de la antigüedad desaconsejaban el consumo de fruta. Los avances científicos que pudieron comprobar sus efectos benéficos en la salud corresponden a la modernidad. Previo a ello, sólo se pudo avanzar con conocimientos intuitivos, a veces contradictorios.

En la Edad Media europea, la salud de la población tenía una serie de debilidades por carencias alimentarias. Uno de los problemas más notables era la insuficiencia de vitaminas. Las élites consumían carnes y pescados, mientras que el pueblo se alimentaba principalmente de cereales y legumbres. Las frutas ocupaban un lugar muy marginal. ${ }^{28}$ Además, algunos autores desaconsejaban su consumo por considerarlas "viandas húmedas". ${ }^{29}$ Por lo tanto, se generaban problemas considerables, particularmente falta de vitamina $D, A$ y $C$, con lo que proliferaban fácilmente las epidemias y diferentes dolencias que afectaban otras partes del cuerpo: vesícula y riñones (cálculos) ojos (ceguera, xeroftalmia, falta de vitamina A) y pérdida de piezas dentarias (escorbuto, deficiencia de vitamina C). ${ }^{30}$

A pesar de no disponer de estudios experimentales, algunos textos asociaban las frutas con la salud y la vida; en la Biblia, por ejemplo, se registran varios casos (Cant 2:5). Intuitivamente se asociaba la fruta con la salud y la vida. Esta idea se presenta también en el relato de las murmuraciones contra Moisés, donde se reflejan las dudas por llevar a la gente a un lugar desierto, sin frutales ni agua (Núm 20:5). Posteriormente, merced a una avanzada al valle de Escol, Moisés demuestra la existencia de los mismos (Éx 13:23). La presencia de los frutales representaba la coronación del viaje y el cumplimiento de las promesas divinas. La fruta aparece en el relato bíblico como un recurso literario para marcar el tránsito del desierto (donde no hay fruta) a la tierra preparada por Dios para el pueblo elegido (donde la fruta está presente).

La cultura musulmana realizó un aporte significativo en el mejoramiento de la salud, mediante la promoción del consumo de frutas. Este enfoque se hizo sentir en el sur de la península ibérica donde "los médicos andalusíes hablan de las propiedades bromatológicas de bastantes especies frutícolas". ${ }^{31}$ En este

27 RAE. Diccionario, t.II, p.842.

28 MENNELL, Francais et anglais a table du moyen age a nos jours, p.66-73.

29 OLIVEIRA, Marques, A. H. A sociedade medieval portuguesa: aspectos de vida quotidiana. Lisboa: A Esfera dos Libros, 2010, p.35.

30 OLIVEIRA, Marques, A. H. A sociedade medieval portuguesa, p.28-32.

31 SÁNCHEZ, Expiración García . Aspectos dietéticos de la alimentación en Al-Andalus. En: Historia y Cultura del islam español (curso de conferencias 1986-87). Granada: Escuela de Estudios Árabes-CSIC, 1988, p.60. 
contexto, el discurso de Las mil y una noches, en el sentido de promover el consumo de frutas, significó un valioso aporte en el mejoramiento de los hábitos alimentarios de la cultura árabe a la sociedad europea.

Las mil y una noches despliega una doctrina sobre la salud y la enfermedad, en la cual la calidad de la alimentación cumple un papel fundamental. En ese sentido, la fruta realiza un aporte significativo, pues contribuye a una nutrición adecuada, a diferencia de otros alimentos. Paralelamente, para resaltar esta función, la obra dedica también un espacio a presentar la fruta - particularmente la manzana - con poderes mágicos y capacidades curativas.

En una obra tan extensa como Las mil y una noches abundan las referencias simbólicas. Pero en algunos casos se entregan definiciones directas, tal como ocurre en la Historia de la Docta Simpatía (noches 270-286). En este relato se pone en boca de una bella y culta mujer las ideas que, desde la perspectiva del libro, corresponden a las definiciones más explícitas sobre la cultura árabe y la religión musulmana. En este contexto se aportan consideraciones sobre la forma más adecuada de cuidar la salud, terreno en el cual se destaca la importancia de los hábitos de higiene y la alimentación sana, donde las frutas representaban un aporte significativo. Docta Simpatía recomienda la fruta como el alimento más sano (279:464). De entre ellas, destaca la cidra y la granada (282:464). Se traza un perfil claro de la función sanitaria de la fruta: junto con el pescado y la carne magra de cordero, los alimentos más saludables eran las frutas. De esta forma, se entregaba una definición clara y franca del valor nutricional. Esta idea se reforzaba también en el plano simbólico, terreno en el cual Las mil y una noches tiene su mayor fortaleza. En efecto, dentro de la variedad de objetos con poderes supra-naturales (caballos y tapices voladores, lámparas maravillosas, aves fabulosas, genios y efrits), se incluye un objeto con capacidades curativas de singular interés para nuestro estudio.

La "Historia de la princesa Nurena-Har y la bella efrita" (noches 792-804) presenta la fruta más valiosa: la manzana curadora. Se trata de una fruta especial, que tiene las cualidades naturales de la manzana, pero en niveles superlativos (696:380). La atribución de poderes sanadores a una manzana, propuesta por este cuento, tuvo su continuación en los imaginarios culturales hispanoamericanos. Así se reflejó, por ejemplo, en los cuentos tradicionales chilenos, donde también aparece la manzana curadora. Entre sus virtudes está la capacidad de volver a la vida a alguien, tal como refleja el cuento El leso. ${ }^{32} \mathrm{Al}$ parecer, este tipo de relatos se arrastran desde el mundo europeo, pues también se encuentra presente la manzana del árbol de la vida en el cuento de los hermanos Grimm The white snake.

32 SAAVEDRA, Yolando Pino. Cuentos folklóricos chilenos. Santiago: Ediciones Universidad de Chile, 1960 , p.311. 


\section{La fruta y el placer de la mesa}

Además de promover los aportes de la fruta en sí misma, para su consumo en fresco, el libro la coloca como medio adecuado para el desarrollo gastronómico. La gastronomía es el "arte de preparar una buena comida". ${ }^{33} \mathrm{El}$ concepto se comenzó a utilizar a mediados del siglo XIX, con raíz etimológica derivada del griego gaster-os, estómago. ${ }^{34}$ En las Las mil y una noches, la preparación de las comidas es un tema relevante, sobre todo la "cocina del palacio". Se presenta como "lujo colectivo" y alcanza un reconocimiento especial en la obra: "gracias a la mesa, el Oriente se da una imagen digna de sí, una imagen gratificante". ${ }^{35}$ La dimensión gastronómica de Las mil y una noches ha alcanzado tanta relevancia popular, que se ha utilizado como nombre para restaurantes de todo el mundo: en Bélgica, Francia e Inglaterra; en Canadá, Estados Unidos y Panamá se pueden encontrar restaurantes llamados "Las mil y una noches", lo mismo que en Chile, Sudáfrica, Australia, España, Marruecos y la India. Los empresarios gastronómicos han coincidido en rescatar el prestigio de esta obra en el imaginario social.

Desde la perspectiva del presente estudio, lo importante es que las frutas se presentan como medio adecuado para el desarrollo de una rica gastronomía. En un primer momento, la fruta requiere atención para su conservación. Debido a sus componentes de agua y azúcar, muchas frutas tienden a descomponerse en poco tiempo, una vez maduras. Por tal motivo, se aplican técnicas de conservación, mediante deshidratación (pasas de uva, higos y dátiles secos) o cocción (dulces, mermeladas). El desarrollo de las técnicas de conservación generó cierta familiaridad en el manejo de la fruta, a partir del cual, se pudo avanzar hacia objetivos más ambiciosos, sobre todo para obtener nuevos y más sofisticados sabores y aromas.

Otras obras literarias también recogían la costumbre de elaborar alimentos a partir de las frutas. En la Biblia hay varias referencias a jugos de uva. En algunos casos esta bebida ocupa el lugar de máximo honor en la corte del monarca egipcio (Gén 40:11); esta bebida no era exclusiva de las elites, sino también estaban al alcance del pueblo elegido, como muestra de la misericordia de Dios: fue el argumento utilizado por Moisés para reclamar la fidelidad de sus seguidores (Dt 32,14). Otra opción era el jugo de granadas (Cant 8:2). También se servían tortas de higo (I Sam 25:18; 30:12; II Sam 16:1; II Re 20:7; I Crón 12:40; Is 38:21), y pastel de pasas (Cant 2:5; I Crón 16:3;

33 RAE. Diccionario, t.I, p.1026.

34 COROMINAS, Joan. Breve Diccionario Etimológico de la lengua castellana. Madrid: Gredos, $3^{\circ}$ ed., $10^{\circ}$ reimpresión, 2000 [1961] p.294.

35 CHEBEL, Malek. Dictionnaire amoureux des Mille et une nuits. Lonrai: Plon, 2010, p.196. 
II Sam 6:19). También era frecuente la referencia al aceite de oliva. Este se usaba para iluminar el tabernáculo con lámparas dedicadas al culto (Éx 27, 20) y como ofrenda sagrada (Éx 29,$40 ; 30,24)$. El rey Salomón pagó parte del templo de Jerusalén con grandes cantidades de aceite de oliva (I Re 5:10). Y dentro de la toponimia sagrada, uno de los lugares más significativos fue el Monte de los Olivos, recurrentemente citado en el Nuevo Testamento.

Continuando con la tradición bíblica, los pueblos árabes mantuvieron y profundizaron esas costumbres. Las frutas se elaboraban para obtener deshidratados, aceites, jugos y dulces. Entre los deshidratados más difundidos estaban las pasas de uva y los higos secos. Los jugos más consumidos eran los sorbetes de manzana, el jugo de uva, la limonada y la leche de almendra. Entre los aceites más relevantes figuran el aceite de almendra, de pistacho $y$, sobre todo, el aceite de oliva. Este ocupa lugares de privilegio tanto por la recurrencia de las menciones, como en el lugar que se les asignó en los relatos. En algunos casos alcanzaron posiciones de singular jerarquía. Basta señalar la importancia del aceite de oliva en la historia de Alí Babá (noches 857-858), o bien, el papel de las aceitunas rellenas en el accidentado romance de Kamaralzaman y la princesa Budur (noches 170-236).

La pastelería era un ámbito muy desarrollado dentro de la elaboración de las frutas. Con los limones se preparaban pasteles, lo mismo que con las granadas. Los dulces se elaboraban con cidras, damascos y, más frecuentemente, con granadas. Los dulces y pasteles de granadas y la pasta de almendras aparecen como las confituras más recurrentes en el conjunto de los relatos. A su vez, estos productos tenían múltiples combinaciones.

En uno de los relatos se incluyen varias confituras: "transparente y rutilante confitura seca de damasco tendida en anchas hojas; dulce seco de cidras con azúcar cande perfumado con ámbar; dulce de dátiles rellenos de clavo y almendra" (32:149). En otro cuento se mencionan "pastas de almendras aromadas con benjuí de las islas cálidas (107:272). También hay otra referencia interesante: "Mahallabia perfumada con esencia de naranjas y salpicada de pistachos triturados y canela" (116:283). Más adelante se refieren a "uvas maceradas y aromatizadas directamente con almíbar de rosas; uvas frescas" (116:283). En otro relato se mencionan "deliciosos pasteles y dulces que se hacen en Alepo, rellenos de piñones y almendras azucaradas" (19:80).

La elaboración de la fruta para conservarla y avanzar hacia una gastronomía más compleja, fue un aporte significativo de la cultura musulmana. Con estas prácticas, se realizó una contribución a la cultura del trabajo, al arte de conservar y preparar los alimentos, y al mejoramiento de la calidad de las comidas. Introducida por los árabes, estas tradiciones fueron trasladadas luego a Europa y América, donde tomarían distintos caminos en su evolución. 


\section{Frutas y lugar de origen geocultural}

Las frutas cumplen también una función identitaria en Las mil y una noches, en el sentido de portar dentro de sí una historia, una relación con su origen geográfico y/o cultural. Las frutas aportan a la identidad de ciudades, pueblos y hasta de familias. Se trata, por lo tanto, de identidades de dimensiones elásticas. Las unidades mayores tienen como características conjuntos más amplios: una ciudad puede estar asociada con la abundancia de frutas en general. Las unidades menores, en cambio, se identifican con productos más específicos, como una receta culinaria. Un ejemplo del lazo entre la fruta y la identidad de una ciudad puede ser el de Damasco. La capital de Siria es identificada, en el texto, por tres atributos destacados: agua, frutales y jardines (54:221) insistiéndose en esta idea (346:546).

La función identitaria de la fruta se refleja también en las indicaciones de procedencia geográfica. Se trata de un asunto de creciente interés, por conectarse después con las denominaciones de origen. La utilización de nombres geográficos para identificar productos y personas fue una práctica muy antigua y universal, asociada al comercio. ${ }^{36}$ La procedencia geográfica era un indicador que permitía valorar los bienes que se transaban en el mercado y facilitar el intercambio con mayor confianza. Poco a poco, se construyeron jerarquías de valor comercial, asociadas a la indicación geográfica. Ya en la Biblia se incluyen referencias al origen geográfico de los productos como cualidad que contribuye a su valor: caballos y lino fino de Egipto; vinos y cedros del Líbano; viñas de Baal-Hamon y En-Guédi; lana de Sacar. Otras obras antiguas también reflejaron esta tendencia, como se refleja en la Odisea, donde se especifica procedencia geográfica de los vinos. Es conocido el valor diferencial que alcanzaron productos de China y Japón, sobre todo objetos de bronce y porcelana, asociados, precisamente, a su origen geográfico; en las culturas clásicas de Grecia y Roma también se desplegaron las indicaciones geográficas para fortalecer el valor de los productos como vasijas, telas y perfumes. También se desarrolló la valoración de los productos alimenticios a partir del origen geográfico, sobre todo castañas, aceites y vinos. ${ }^{37}$ En Roma, los vinos más "afamados fueron el falerno, el másico, el albano, el cécubo, el setino; todos estos vinos se denominaron, igual que hoy, por su lugar de origen". ${ }^{38}$

36 ALMEIDA, Alberto Ribeiro de. A autonomia jurídica da denominação de origen: uma perspeciva transnacional. Una garantia de qualidade. Coimbra: Wolters Kluwer, 2010, p.15.

37 ALMEIDA, Alberto Ribeiro de. A autonomia jurídica da denominação de origen, p.18-28.

38 LEJAVITZER, Amalia. El vino en la gastronomía romana antigua: clases y usos en De re coquinaria de Apicio. Universum, Talca, n.22, v.1, p.15, 2007. 
En Las mil y una noches se refleja también una tendencia a valorar algunas frutas, de acuerdo a su zona de cultivo y producción. En la historia del "cargador y las tres muchachas", se muestra a un joven que, deseoso de complacer a las damas, concurre al zoco para comprar frutas, las cuales, para mayor realce, tenían sus propias denominaciones de origen: el pedido incluía "manzanas de Siria, membrillos osmaníes, melocotones de Omán, jazmines de Alepo, nenúfares de Damasco, limones de Egipto, cohombros del Nilo, cidras sultaníes" (9:36). En otro relato, las manzanas se van a buscar de Bagdad a Basora (Noches 18-19). Más adelante, en una suerte de "oda a las frutas", se entregan los fundamentos que hacen apreciable a cada una de ellas; en el caso de las peras se indica, precisamente, el valor agregado por el lugar de origen: “¡Oh jóvenes, todavía vírgenes y ácidas al gusto, oh sinaíticas, oh jónicas, oh alepinas! Sois siempre deseables exquisitas a nuestro gusto" (656:204).

Más sutil, pero no menos importante, es la función identitaria de la fruta dentro de una familia, particularmente en la tradición gastronómica que se puede desarrollar en ella. Sobre todo porque la forma de elaboración de las frutas, al transmitirse dentro de los miembros de un mismo grupo, podía transformarse, en caso de dispersión, en un medio de comunicación para volver a encontrarse. Esta es la clave de las historias de Hassan Badreddin (Noches 19-24) y de la princesa Budur (Noches 170-236).

El primer relato da cuenta de una familia cuyos miembros quedaron dispersos en tres ciudades muy distantes entre sí: Basora, Damasco y El Cairo. La reconstrucción del lazo, la memoria y la identidad familiar fue posible, precisamente, por una comida de frutas: el pastel de granadas y almendras. En la segunda historia, se reitera la dispersión familiar hasta que, una vez más, a través de las frutas (en este caso, tarros de aceitunas) se produce el reconocimiento y luego, el reencuentro de los amantes (227:405-406).

La función identitaria de la fruta guarda relación con su origen tanto geográfico como cultural. Desde el punto de vista geográfico, el lugar donde se cultiva la planta frutal se reconoce como información relevante que permite identificar y valorar la fruta. En forma complementaria, también es importante el origen cultural - esta vez no un lugar fijo, sino una familia o un grupo social - que crea una forma de elaborar la fruta mediante una receta gastronómica que constituye una identidad. En ambos casos se produce un fenómeno parecido: el lugar geográfico o el grupo social que originan la fruta y le dan valor, después de recorrida la trayectoria, experimentan el efecto exactamente inverso: son valorizadas por la fruta. 


\section{La fruta y los espacios de poder y prestigio: el jardín y el salón}

Las frutas y los frutales tienen también una función bioespacial, por la cual, contribuyen a la construcción de espacios físicos, políticos, sociales y culturales, donde el prestigio, el poder y las relaciones humanas adquieren relevancia. El papel de los alimentos en la vida sociocultural de Las mil y una noches ya ha motivado algunos estudios específicos, como por ejemplo, para el caso del café. ${ }^{39}$ De todos modos, las frutas tuvieron un papel relevante en este campo, que conviene mirar en su conjunto.

La definición de un espacio social a partir de la presencia de una planta frutal se encuentra presente en el relato bíblico, con dos sentidos diferentes: sagrado y natural. Por un lado, la fruta se utiliza para construir un lugar sagrado. Para decorar templos, altares, vestiduras y objetos dedicados al culto, se emplean representaciones de frutas, sobre todo almendras y granadas. Para rendir honores al Arca de la Alianza se fabricó un candelabro de oro puro con cuatro cálices en forma de flor de almendro; además, el candelabro tenía seis brazos, cada uno de ellos decorado con otros tres cálices con forma de flor de almendro (Éx 37:17-21). El manto del sacerdote debía tener, en el ruedo inferior, granadas (Éx 28:33-34; 39:24-26). También se utilizaron formas frutales para decorar el templo de Salomón. El pórtico del templo tenía dos grandes columnas de bronce, de cinco metros de altura, con sus respectivos capiteles, de un metro y medio. En su parte superior, los capiteles estaban revestidos con reticulados de cadenillas o trenzas. Precisamente allí se colocaron los motivos frutales (I Re 7:17-19). En total se fabricaron cuatrocientas granadas de bronce bruñido para decorar las columnas (I Re 7:42-46; I/ Crón 4:13). Esta decoración contribuyó a jerarquizar el templo, y formó parte de los detalles de calidad que significaron el orgullo del pueblo elegido durante su apogeo, y su humillación tras la invasión de los caldeos y la destrucción del templo (II Re 25:13-17). La caída de Jerusalén y la deportación del pueblo elegido a Babilonia es uno de los acontecimientos más nefastos de la historia bíblica. Como recurso literario, para lograr representar mejor la tensión dramática de este episodio, el anónimo autor del texto apela, precisamente, al detalle de los objetos destruidos del templo, entre los que menciona las granadas de bronce que adornaban las columnas.

Los detalles del candelabro del Arca de la Alianza, de las vestiduras sacerdotales y del templo de Salomón sirven para visibilizar la importancia que los autores de la Biblia otorgaron a las frutas como medio para realzar la importancia de determinado espacio, particularmente un lugar sagrado: los

39 SHOSHAN, Boaz. Social life and popular culture in the Arabian Nights. In: MARZOLPH, Ulrich e LEEUWEN, Richard van. (eds.) The Arabian nights encyclopedia, p.50-54. 
objetos mencionados se encuentran entre los de mayor valor en la historia de la salvación del pueblo elegido. Evidentemente las frutas servían para realzar la relevancia de un lugar sagrado. Pero, paralelamente, también se utilizaron para destacar espacios naturales. Con frecuencia se hacen referencias a parras e higueras como lugares donde se puede encontrar una sensación de paz, tranquilidad y resuello (Neh 14:12; I/ Sam 5:3; I/ Crón 14:2).

El espacio físico de los frutales era, esencialmente, el jardín. Se trata de un espacio social que se desarrolló en forma paralela al huerto, pero con intención estética y política: el jardín se fue transformando en uno de los símbolos del poder. Durante el siglo XII el jardín era definido como un lugar de flores y recreación. Más adelante se precisó que el jardín se desarrollaría como un "huerto de recreación, compuesto de diversas flores y hierbas olorosas". En la Edad Media, los países europeos se orientaron más hacia el huerto y a medida que avanzaron hacia el Renacimiento, se produjo la gradual transformación del huerto en jardín. ${ }^{40}$ En este proceso, los árabes realizaron una contribución relevante.

El liderazgo musulmán en el desarrollo de los jardines dentro de Europa se produjo en plena Edad Media. La mezquita de Córdoba data de 786 y junto a ella se levantó el patio de los naranjos; los jardines del Generalife fueron construidos durante el reinado de Ismail (1314-1325); los de la Alhambra se levantaron durante Yusuf I (1333-1354). Naturalmente, hubo muchos cambios en estos jardines; incluso en un comienzo, al parecer en vez de naranjos había otros frutales en la mezquita cordobesa. ${ }^{41}$ Pero lo importante es destacar el liderazgo musulmán en la introducción y expansión de los jardines dentro de Europa. Esos jardines hispanoárabes fueron un motor para desencadenar el proceso por el cual el huerto medieval fue, progresivamente, transformándose en jardín. Los jardines que los musulmanes levantaron junto a los palacios, se transformarían después en paradigmas para el resto de Europa. Los jardines del Generalife, el patio de Lindaraja en los palacios Nazaríes y los rincones de granados y naranjos en la Alhambra son buenos ejemplos. Su articulación con la arquitectura y el arte general, alcanzaron un prestigio sin precedentes que no tardó en marcar modas y tendencias. En 1510 el rey Manuel I de Portugal contrató un jardinero español en Valencia para construir jardines en los palacios. ${ }^{42}$ En 1457 los Médici impulsaron la construcción de la Villa Careggi, embellecida con "naranjos y limoneros cultivados en cubetas y alineados en las

40 SILVA, José Custódio Vieira da. Espaços e lugares: o paço. In: MATOSO, José. (dir.). História da vida privada em Portugal, p.87.

41 CADENA, Francisco Páes de la. Historia de los estilos en jardinería.

42 SILVA, José Custódio Vieira da. Espaços e lugares, p.86. 
calles del jardín". ${ }^{43} \mathrm{Al}$ comenzar el siglo XVII, junto al palacio Pitti se levantó la limonaia. Este proceso culminaría unas décadas más tarde con los jardines de Vaux Le Vicompte y luego, en la Orangerie del palacio de Versalles.

El liderazgo de los árabes en el desarrollo de los jardines guarda relación con un conjunto de causas sociales, económicas, políticas y culturales. El temprano dominio de las técnicas hidráulicas generó las bases tecnológicas para poder construir los jardines. Los conocimientos de botánica, geometría y astronomía también contribuyeron a este proceso. Paralelamente, las limitaciones ideológicas del arte islámico, que prohibían representar figuras humanas y animales, orientaron las energías de la creatividad artística hacia las representaciones abstractas y a la búsqueda de la belleza en los jardines. ${ }^{44}$ La llegada de los árabes a la península ibérica significó la propagación de estos conocimientos, y promovió el desarrollo de un importante avance de la agronomía, sobre todo en Andalucía. ${ }^{45}$ Asimismo, el antiguo esplendor de los jardines árabes, que se extendió por tres continentes, apenas se puede conocer en la actualidad a través de los vestigios materiales y de los cuentos de Las mil y una noches. ${ }^{46}$ De allí la relevancia de abordar este tema a partir del libro que estamos analizando.

El jardín, por definición, requería flores. La presencia allí de las plantas frutales se justificaba por la concepción de los árabes con respecto a la dimensión estética que aportaban algunos frutales, particularmente los cítricos. Las flores y los perfumes, más que jerarquía, respondían a la idea de sensualidad del jardín paradisíaco árabe. Allí se destacaban los frutales por su aporte de perfume, belleza y alimento. Su presencia servía para jerarquizar el lugar, sobre todo como marco para los palacios y casas principales. En lugares cerrados, las frutas también contribuían a crear un espacio significativo. Sobre todo porque su presencia, asociada a otros objetos de prestigio, como vajillas de oro y plata, tapices y alfombra, contribuía a crear esa atmósfera refinada y distinguida que se requería como escenario para realzar la jerarquía de los personajes y el interés del relato. Había también un tercer espacio, de carácter comercial, signado por la abundante presencia de la fruta: el zoco.

El zoco de los fruteros era un elemento significativo en la vida socioeconómica de las comunidades árabes reflejadas en Las mil y una noches. Estas descripciones tenían un correlato directo con la realidad pues, los estudios históricos focalizados en Marruecos y Al Andaluz revelaron la trayectoria de

43 CADENA, Francisco Páes de la. Historia de los estilos en jardinería, p.132.

44 BARIDON, Michel. Los jardines: paisajistas, jardineros, poetas. Islam, Edad Media, Renacimiento, Barroco.

Paris: 1998. Edición española: Madrid: Abada, 2005. Traducción de Juan Calatrava, p.16-26.

45 BOLENS, Lucie. Agrónomos andaluces de la Edad Moderna. Granada: Universidad, 1994 [1981].

46 BARIDON, Michel. Los jardines, p.38. 
estos espacios comerciales, donde la figura del frutero se distinguía como sujeto histórico. ${ }^{47}$ En Las mil y una Nnches se apela con frecuencia a la vida comercial de los zocos, como escenario de los relatos; a su vez, los zocos eran espacios comerciales especializados: había zocos de joyeros, pasteleros, tenderos, y también de fruteros. Las referencias a ellos muestran singulares notas de color (232:408). Además del frutero, la obra presenta otros sujetos históricos especializados, tal como el caso del almendrero (9:36).

En Las mil y una noches el jardín es, a la vez, espacio y meta espacio. Este recurso no es exclusivo de la cultura musulmana ni tampoco de Las mil y una noches; también se encuentra presente en otras obras, como por ejemplo, el Corán. El jardín tiene una doble identidad: es un lugar de existencia real y efectiva, en la vida natural y a la vez, es una utopía, es el sitio de bienaventuranza, más allá de la muerte. En ese sentido, la lógica del relato de Las mil y una noches es coherente con las enseñanzas de El Corán. Este libro sagrado enseñaba que el premio preparado por Alá para las personas buenas era el Jardín de Iram, caracterizado por fuentes, flores, frutales y bellas mujeres. En línea con esta cosmovisión de la vida sobre natural, los relatos de Las mil y una noches se refieren recurrentemente al tema. Así, por ejemplo, en la historia del negro Bakhita, (noches 41 y 42) un jeque encuentra a un pobre hombre en la puerta del hospital de Bagdad y resuelve atenderlo, justamente, para alcanzar ese premio ultra terrenal.

Paralelamente al Jardín escatológico, se valora también el jardín natural, que existe en la vida presente. Los relatos de Las mil y una noches se desarrollan en un contexto coherente de usos y costumbres, en las cuales el jardín representa un lugar de singular importancia. Se trata de un espacio contiguo al palacio, en el cual mediante el cultivo de frutales y plantas aromáticas se procura alcanzar la belleza a partir de sensaciones para los distintos sentidos: el color de las flores para la vista; el rumor de las fuentes y el cantar de los pájaros para el oído, y el perfumen de flores y los frutales para el olfato. Para ello se requería una base estructural generada por árboles, arroyos y manantiales. Se generaba así un conjunto de gran belleza y atractivo, que servía para realzar el poder y prestigio de los propietarios, ya fueran autoridades (emires, sultanes, visires) o comerciantes exitosos (255:432).

El jardín era, esencialmente, un escenario del poder y un espacio de socialización. En el jardín se convocaba a los invitados, se los recibía, y se realizaban las comidas. Estos usos y costumbres aparecen a lo largo de los distintos relatos, particularmente en la Historia del Negro Kafur (noche 38). Allí se entregan detalles de esta tradición del uso del jardín como espacio social.

47 SÁNCHEZ, Expiración García. Aspectos dietéticos de la alimentación en Al-Andalus. 
El cultivo de las plantas frutales tuvo uno de sus lugares de mayor prestigio en el Jardín de las Delicias. Corresponde a la historia de la bella esclava Dulce Amiga, y se relató en la noche n.34. Ubicado junto al Palacio de las Maravillas y propiedad del califa Harún Al-Raschid en Bagdad, el Jardín de las Delicias era cuidado por jardineros especializados. Además de fuentes y flores, había parras y árboles frutales cargados de magníficas frutas: damascos, higos, cidras, limones y ciruelas (34:166-167).

Dentro de la función bioespacial de las plantas frutales, un papel singular cupo a los cítricos, particularmente naranjos y limoneros. Un relato presenta al protagonista "refrescado por la brisa que se había perfumado en los limoneros floridos". (65:232) Otra descripción insiste en el aporte de belleza de los cítricos (769:343-344). Estas imágenes se reiteran en la "Historia del Jeque de la Mano Generosa", cuando los invitados son recibidos en un salón de reuniones, que se encuentra, precisamente, en medio del jardín (873:503-504). En algunos casos, se adoptaba por una descripción minimalista: se omitían los demás elementos, y sólo se enfocaba la fruta, para destacar la importancia de un espacio. Un buen ejemplo es el palacio de Simbad el Marino, donde se recibe al visitante con bandejas de almendras y jugos de uva (290:473).

En la vida familiar y social, la fruta permite expresar la valoración de la otra persona, a través de lenguaje simbólico. La acción de ofrecer frutas, era un código compartido de honor, reconocimiento y valoración del invitado. Era un detalle personal y relevante. Con la fruta se presentaba un mensaje de reconocimiento del otro. Era una forma de manifestar interés, lealtad y amor. En algunos casos, para realzar este acto, la fruta se servía en vajillas lujosas, como por ejemplo, elegantes jarrones, bandejas de plata y copas de porcelana. En la historia de Ghanem se explica que, tras quedar encantado por la belleza de una mujer, procedió a agasajarla con estos medios (40:186). La fruta era una comida excelente para seducir a una mujer y complacer a las autoridades. En la comida que comparten el rey Omar Al-Nemán y la reina Abriza, se sirven "bebidas en grandes copas de oro y cristal, y platos de frutas, almendras, avellanas" (51:214). Esa noche, iniciada con vino y frutas, terminó con pasión y sexo.

Por extensión, una forma de manifestar el amor por una persona querida era, justamente, servirle o enviarle frutas. Así lo refiere el protagonista de un relato que envía a casa de su amada diferentes clases de fruta y almendra como regalo precioso (23:113). Más entusiasmo tenía otro amante que, para complacer a su esposa, atravesó el desierto, desde Bagdad hasta el golfo, para comprarle frutas (18:77). En otro relato, se insiste en la fruta como medio para conquistar a la mujer amada (27:121). 


\section{Conclusión}

Si los fruticultores, botánicos y agrónomos musulmanes propagaron las plantas frutales hacia Europa Medieval, la eficacia de su propuesta se vio acompañada, silenciosamente, por la labor invisible y eficaz de los narradores de cuentos que, a través de los relatos de las Mil y Una Noches, situaron a las plantas frutales en un lugar de prestigio de alcance universal. La incorporación de la fruta a la narración literaria había comenzado con cierta fuerza en los escritos bíblicos, pero luego decayó en la literatura medieval europea. Por contraste, los pueblos árabes mantuvieron esta tradición, la ensancharon, enriquecieron y profundizaron, para trasmitirla de nuevo a Europa. Los musulmanes actuaron como intermediadores bio-culturales, en el sentido de impulsar la propagación y valoración de las frutas y plantas frutales.

Después del descubrimiento de América, los españoles realizarían un papel homólogo, al trasladar las plantas y adaptarlas a los climas y suelos de las Indias, y transmitir los saberes culturales requeridos para su cultivo, elaboración y valoración, todo ello fundado en la herencia musulmana. Así llegaron las plantas a las colonias de España y Portugal, las cuales, medio mileno después, emergieron como potencias exportadoras de fruta como Chile y Brasil.

Alejandro Magno primero y el Imperio Romano después, promovieron un primer ciclo de expansión de los frutales por Europa. Varias especies ingresaron, se propagaron, se cultivaron y consumieron en Europa a partir de entonces. Pero tras el derrumbe del Imperio, se produjo un retroceso. Se deterioraron las condiciones políticas, sociales y comerciales para el mantenimiento de estos sensibles cultivos. Los pequeños espacios de seguridad, protegidos por castillos y monasterios de Europa medieval, lograron mantener en un grado menor la tradición de cultivo de huertos y jardines. Pero en líneas generales, la calidad de la alimentación se estropeó: Muy pocas frutas llegaban del campo a la mesa. En este contexto se produjo el segundo ciclo de expansión de los frutales, liderado esta vez por los árabes y la cultura musulmana. Este movimiento operó a través de dos caminos paralelos: el natural y el cultural.

La expansión de los frutales en su dimensión natural se llevó adelante, principalmente, en los huertos y jardines musulmanes (de árabes y bereberes) en al-Andalus. Los hortelanos y jardineros árabes realizaron una tarea intensa y eficaz de adaptación de las plantas frutales a los climas y suelos del sur de Europa, a la vez que sus botánicos y agrónomos andalusíes estudiaban sus características y las difundían a través de los Tratados. De esta forma, ellos introdujeron y propagaron las plantas y los conocimientos para manejarlas, incluyendo la forma de reproducción, poda, riego, abono, injerto y demás 
trabajos específicos. Esa actividad se complementó con el desarrollo de la dimensión cultural de las plantas: en este sentido fue decisivo su aporte al proceso de construcción de una cultura de la apreciación de los frutales. Se colocaron estas plantas en el centro del escenario de su literatura, particularmente en Las mil y una noches. En esta obra, las frutas y los frutales se revisten de magia y encanto. Se asocian con la sensualidad del poder, la belleza de lo sublime y la turgencia de la vida y el sexo. Los frutales tienen funciones mágicas que elevan de categoría lo que se pone en contacto con ellos: la mujer es más bella, el jardín es más atractivo, el alimento más sano, la gastronomía más deliciosa.

En una Europa que venía saliendo de la Edad Media, y se encontraba en el proceso de reconstruir sus instituciones, sus conocimientos, su valoración de la vida y la belleza, Las mil y una noches impulsó la puesta en valor de los frutales, y con ello, aportó al mejoramiento de las condiciones de vida de los grupos humanos.

Introducidos estos elementos en Europa, fueron trasladados después a las Indias y, en las regiones donde los nichos ecológicos lo permitían, se pudo ver el despliegue de este proyecto de valoración de la fruta y los frutales, la cultura del trabajo, la agricultura intensiva, la agroindustria y la gastronomía. Doña Agustina Echegaray, en el remoto Reino de Chile, dedicó buena parte de su energía a cultivar sus plantas frutales porque eran importantes para ella. No le daban beneficios económicos proporcionales a su trabajo. Pero algo interno la impulsaba a estar cerca de sus plantas, a cuidarlas con cariño y legarlas a sus hijos. Había un mágico lazo cultural que le hacía pensar y sentir que allí, entre sus granados y naranjos, latía algo valioso. 